\title{
Rapid Mechanisms for Generating Genome Diversity: Whole Ploidy Shifts, Aneuploidy, and Loss of Heterozygosity
}

\author{
Richard J. Bennett ${ }^{1}$, Anja Forche ${ }^{2}$, and Judith Berman ${ }^{3,4}$ \\ ${ }^{1}$ Department of Molecular Microbiology and Immunology, Brown University, Providence, Rhode Island 02912 \\ ${ }^{2}$ Department of Biology, Bowdoin College, Brunswick, Maine 04011 \\ ${ }^{3}$ Department of Genetics, Cell Biology, and Development, University of Minnesota, Minneapolis, \\ Minnesota 55455 \\ ${ }^{4}$ Department of Molecular Microbiology and Biotechnology, George Wise Faculty of Life Sciences, Tel Aviv \\ University, Ramat Aviv 69978, Israel \\ Correspondence: richard_bennett@brown.edu
}

\begin{abstract}
Human fungal pathogens can exist in a variety of ploidy states, including euploid and aneuploid forms. Ploidy change has a major impact on phenotypic properties, including the regulation of interactions with the human host. In addition, the rapid emergence of drug-resistant isolates is often associated with the formation of specific supernumerary chromosomes. Pathogens such as Candida albicans and Cryptococcus neoformans appear particularly well adapted for propagation in multiple ploidy states with novel pathways driving ploidy variation. In both species, heterozygous cells also readily undergo loss of heterozygosity $(\mathrm{LOH})$, leading to additional phenotypic changes such as altered drug resistance. Here, we examine the sexual and parasexual cycles that drive ploidy variation in human fungal pathogens and discuss ploidy and $\mathrm{LOH}$ events with respect to their far-reaching roles in fungal adaptation and pathogenesis.
\end{abstract}

P oidy change is a common attribute of eukaryotes and is often associated with sexual reproduction. During mating, fungal cells in one ploidy state typically conjugate with cells of identical ploidy, resulting in an overall doubling in genome size. Subsequent ploidy reduction can occur via meiosis, in which one round of DNA replication is followed by two successive rounds of DNA division, effectively halving DNA content in the cell. Ploidy changes can affect basic cellular properties such as cell

size, surface-to-volume ratio, genome stability, and transcriptional output (Galitski et al. 1999; Storchova et al. 2006; Otto 2007; Wu et al. 2010). Furthermore, many species preferentially exist in one ploidy state over another. This is exemplified by the model yeasts Saccharomyces cerevisiae and Schizosaccharomyces pombe, in which $S$. cerevisiae favors propagation in the diploid state, whereas $S$. pombe prefers to propagate in the haploid state (Gerstein and Otto 2009). Accordingly, S. cerevisiae cells show a

Editors: Arturo Casadevall, Aaron P. Mitchell, Judith Berman, Kyung J. Kwon-Chung, John R. Perfect, and Joseph Heitman Additional Perspectives on Human Fungal Pathogens available at www.perspectivesinmedicine.org

Copyright (C) 2014 Cold Spring Harbor Laboratory Press; all rights reserved; doi: 101101/cshperspect.a019604

Cite this article as Cold Spring Harb Perspect Med 2014;4:a019604 
R.J. Bennett et al.

transient haploid state, whereas $S$. pombe cells show a transient diploid state. The fitness advantages associated with propagation in higher or lower ploidy states, however, remain debated in the field (Gerstein et al. 2006; Gerstein and Otto 2009; Zörgö et al. 2013).

Cell ploidy changes can be introduced by mechanisms other than a conventional sexual cycle. For example, in Candida albicans, Cryptococcus neoformans, and some mammalian cell types, endoreduplication effectively doubles genome content via DNA replication without subsequent segregation of chromosomes (Puig et al. 2008; Lee et al. 2009; Ullah et al. 2009; Fox and Duronio 2013; Zielke et al. 2013). Parasexual reproduction, in which ploidy reduction occurs via a nonmeiotic mechanism, also occurs in several fungal species (Papa 1973, 1978; Geiser et al. 1998; Bennett and Johnson 2003; Lee et al. 2010; Dyer and O'Gorman 2012; Seervai et al. 2013). In C. albicans, mating between diploid cells of opposite mating type yields tet- raploid cells (Hull and Johnson 1999; Hull et al. 2000; Magee and Magee 2000) that return to the diploid state by a parasexual program of "concerted chromosome loss," yielding progeny cells with a wide variety of karyotypes (Bennett and Johnson 2003; Forche et al. 2008).

Aneuploidy also is frequently observed in fungal species and is defined as cells containing an unbalanced number of chromosomes. This includes both imbalances in the number of whole chromosomes and chromosome segments (Fig. 1). Interestingly, aneuploidy has been observed in somatic mammalian tissues including the liver and brain (Iourov et al. 2010, 2013; Duncan et al. 2012; Duncan 2013). Although the presence of aneuploid chromosomes often compromises fitness when measured under optimal growth conditions (Torres et al. 2008; Pavelka et al. 2010), aneuploidy promotes phenotypic variation and specific aneuploidies can confer growth advantages under specific conditions (Fig. 1). This is well docu-

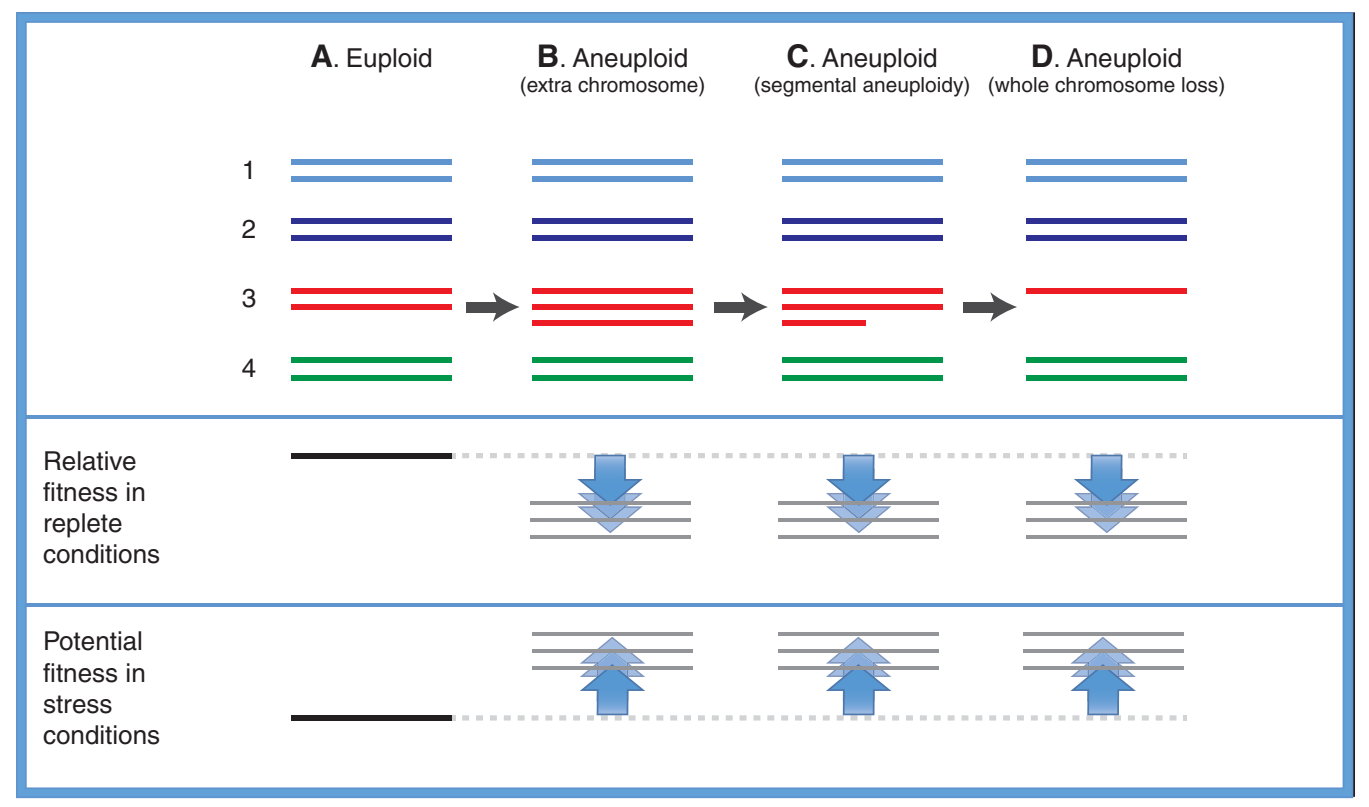

Figure 1. Comparison of fitness attributes in a euploid diploid and aneuploid derivatives. Upper panel: $(A)$ A euploid diploid with four chromosomes. Aneuploidies can occur in the form of supernumerary chromosomes $(B)$, segmental aneuploidies (gains or losses) $(C)$, or loss of whole chromosomes $(D)$. Lower panel: In general, most aneuploid strains show fitness defects under replete (nonstressful) culture conditions relative to the euploid strain. Although any given aneuploidy is unlikely to provide a fitness advantage under a particular condition, specific aneuploidies may provide a fitness advantage under specific environmental stress conditions. 
Fungal Ploidy and Parasexual Cycles

mented for S. cerevisiae, as well as for C. albicans and C. neoformans (Berman 2010; Pavelka et al. 2010; Sionov et al. 2010; Semighini et al. 2011; Sheltzer et al. 2011; Ni et al. 2013). Importantly, in multiple fungal species, specific aneuploidies are directly responsible for the drug-resistant phenotypes of clinical isolates (Selmecki et al. 2006, 2008; Sionov et al. 2010, 2013; Ngamskulrungroj et al. 2012a). Overall, aneuploidy appears to be a conserved mechanism by which eukaryotic cells can rapidly adapt to stressful environments (Selmecki et al. 2006, 2008; Rancati et al. 2008; Pavelka et al. 2010; Yona et al. 2012; Zhu et al. 2012; Tan et al. 2013).

In this work, we review how sexual, parasexual, and asexual mechanisms contribute to karyotypic variation through ploidy shifts, aneuploidy, and loss of heterozygosity (LOH) events in human fungal pathogens. We also address the wide-ranging consequences of these changes for fitness of the fungus, resistance to environmental stress, and interaction with the human host.

\section{PLOIDY SHIFTS VIA SEXUAL AND PARASEXUAL CYCLES}

\section{Ploidy Changes Mediated by Sex}

The best-characterized mechanism of ploidy change is sexual reproduction, which is thought to have evolved once very early in the eukaryotic lineage. Thus, factors regulating meiosis and recombination are conserved from fungi to man (Keeney 2001; Ramesh et al. 2005; Schurko and Logsdon 2008). Our understanding of sex has been greatly bolstered by studies in unicellular model yeasts such as $S$. cerevisiae and $S$. pombe. In both species, mating occurs between haploid cells of opposite mating type, generating diploid products that subsequently undergo meiosis. Completion of meiosis is accompanied by sporulation and the formation of recombinant, haploid progeny (Fig. 2) (Yamamoto 1996; van Werven and Amon 2011).

In $S$. cerevisiae and $S$. pombe, as in most sexual fungal species, mating and meiosis are regulated by genes encoded at the mating-type $(M A T)$ locus. This locus contains transcription factors that are master regulators of cell-type specification, ensuring that only haploid cells of opposite mating type undergo conjugation and that only diploid cells are competent to undergo meiosis (Yamamoto 1996; Galgoczy et al. 2004; Bennett et al. 2005; Sherwood and Bennett 2009; van Werven and Amon 2011). Complete sexual cycles also have been established for two of the most prominent human fungal pathogens, the basidiomycete C. neoformans (Kwon-Chung 1975, 1976a,b) and the filamentous ascomycete Aspergillus fumigatus (O'Gorman et al. 2008) (for detailed reviews of sex in fungi, see Lee et al. 2010; Ni et al. 2011; Ene and Bennett 2014). In both pathogens, heterothallic mating between opposite mating types takes place, and mating is strictly regulated by nutritional cues.

In C. neoformans, pheromone signaling drives fusion of $\mathbf{a}$ and $\alpha$ cells and results in the formation of a heterokaryon, in which binucleate cells grow as filaments. Formation of the dikaryotic stage is dependent on the Sxil $\alpha /$ Sxi2a homeodomain regulatory complex encoded at the mating locus (Hull et al. 2002, 2005; Kruzel and Hull 2010). Nuclei in the dikaryon subsequently fuse during basidium development to form four meiotic products, which then divide by mitosis to generate chains of basidiospores.

Interestingly, homothallic mating has been observed in a number of human fungal pathogens including $C$. neoformans. In this species, unisexual mating of $\alpha$ cells can produce $\alpha / \alpha$ diploids, and subsequently results in the formation of recombinant haploid $\alpha$ progeny (Fraser et al. 2005; Lin et al. 2005). Homothallism has been observed in other human fungal pathogens as well (discussed below), indicating that it is a frequent mechanism used by pathogens to produce diversity. It is perhaps particularly beneficial for $C$. neoformans for which the vast majority of clinical and environmental isolates are of the $\alpha$-mating type (Kwon-Chung and Bennett 1978; Casadevall and Perfect 1998).

In $A$. fumigatus, heterothallic mating between MAT1-1 and MAT1-2 cells results in the formation of sexual fruiting bodies (cleistothecia) containing ascospores. Progeny analy- 
R.J. Bennett et al.

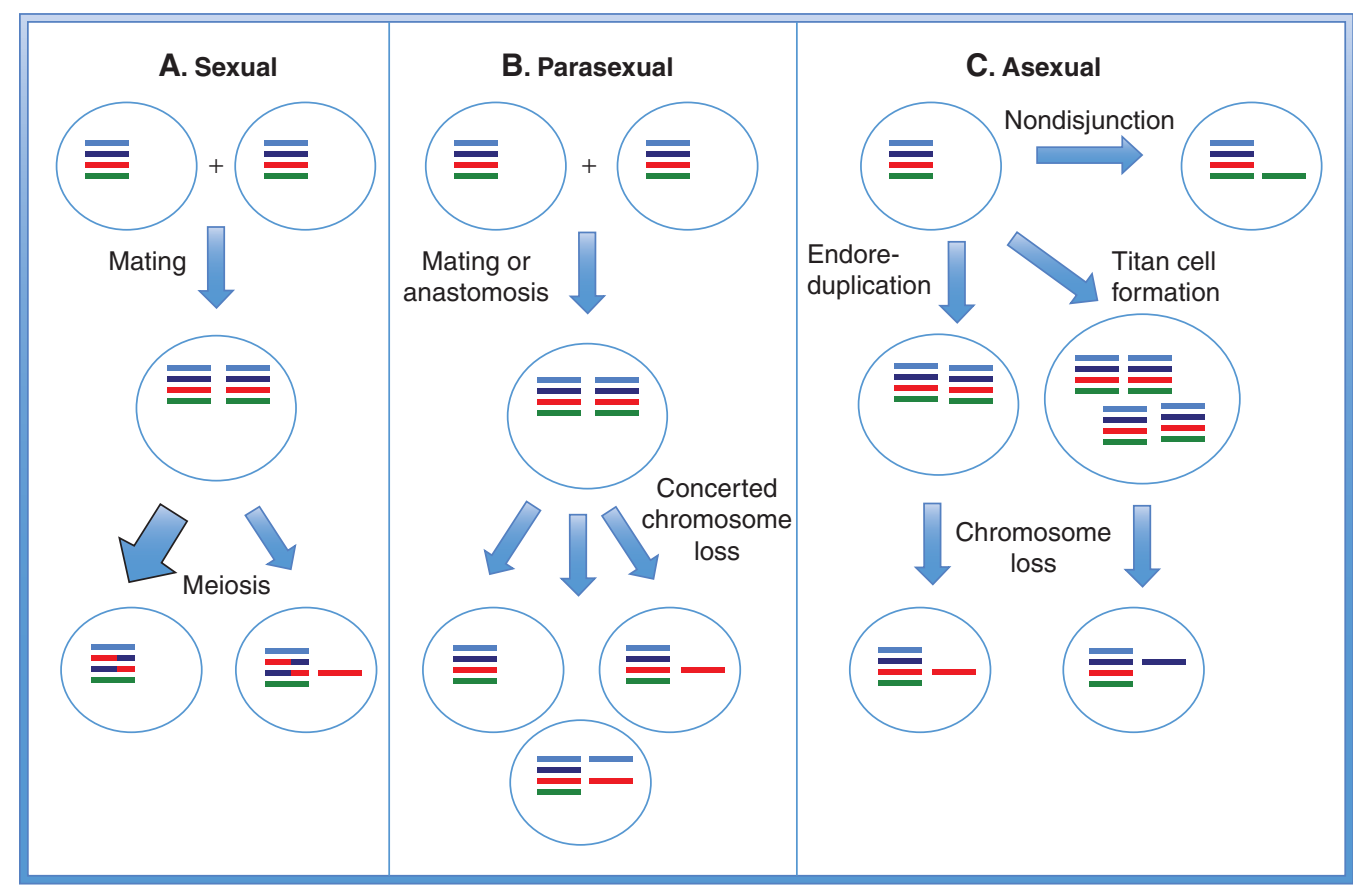

Figure 2. Genomic changes that can accompany sexual, parasexual, and asexual processes. (A) Sexual mating and subsequent meiosis typically results in the formation of recombinant euploid cells, although aneuploidy also is observed in a subset of progeny. (B) Parasexual reproduction involves fusion of complementary cells (by mating or anastomosis) followed by concerted chromosome loss, resulting in the formation of many aneuploid forms in addition to euploid progeny. Recombination is less frequent than in meiosis. $(C)$ Asexual mitotic divisions also can change genomic content, by either chromosome missegregation, endoreduplication, or titan cell formation. Subsequent (asexual) ploidy reduction is expected to include aneuploid products.

sis revealed extensive genetic recombination, a hallmark of conventional meiosis (O'Gorman et al. 2008). Mating was discovered following coincubation of parent cells for 6 months on parafilm-sealed oatmeal plates at $30^{\circ} \mathrm{C}$ in the dark (O'Gorman et al. 2008), showing the highly stringent conditions often required for fungal mating. Recently, more fertile mating strains of A. fumigatus have been identified (Sugui et al. 2011).

Multiple studies indicate that ploidy change itself is a potent modulator of both cell behavior and pathogenesis. Comparison of haploid and diploid C. neoformans cells found that haploid cells were generally more virulent than diploid cells in a murine inhalation model of cryptococcosis (Lin et al. 2008). However, in an alternative infection model, diploids were as virulent, if not more virulent, than corresponding haploid forms (Toffaletti et al. 2004). In the rare human pathogen Aspergillus nidulans, a close relative of $A$. fumigatus, diploid strains were more virulent in mice than the corresponding haploid strains (Purnell and Martin 1973).

\section{Ploidy Change Mediated by Parasexual Reproduction}

Parasexual reproduction is defined as ploidy change without meiosis and is often accompanied by mitotic recombination. Parasexuality was first described by Guido Pontecorvo in the 1950s while investigating $A$. nidulans (Pontecorvo et al. 1953a,b; Pontecorvo and Sermonti 1954). In this species, rare fusion of hyphae can occur (anastomosis), resulting in the formation of a heterokaryon. Subsequently, fusion of haploid nuclei yields relatively stable diploid 
Fungal Ploidy and Parasexual Cycles

cells, which can produce haploid recombinants by mitotic crossing-over and loss of whole chromosomes (Fig. 2). Mitotic recombination during this parasexual cycle therefore results in the nonsexual exchange of genetic material. Since the pioneering work of Pontecorvo, similar parasexual cycles have been found in other fungal species such as A. fumigatus (Berg and Garber 1962), indicating that some species can undergo both sexual and parasexual reproduction.

The potential benefits of a parasexual cycle have been elegantly shown by Schoustra and coworkers who revealed that extended culturing of $A$. nidulans diploid strains resulted in higher fitness than equivalent culturing of haploid strains (Schoustra et al. 2007). In this case, diploids accumulated recessive deleterious mutations that only became beneficial when "unmasked" in recombinant haploid populations. This illustrates the phenomenon of sign epistasis, in which mutations that are individually neutral or deleterious to the organism can be beneficial when present in combination. Diploid cells can act as a reservoir of such recessive mutations, and subsequent reduction to haploidy allows unmasking of these mutations, enhancing overall fitness. Parasex, and its ability to mediate changes in ploidy, can therefore promote adaptation even in the absence of a conventional sexual program.

C. albicans, the most prevalent human pathogen, also possesses a parasexual mating program. This species was long thought to be an obligate diploid with no capacity for mating or sexual reproduction. However, C. albicans undergoes both homothallic and heterothallic mating, in which diploid cells of the same or opposite mating type undergo conjugation to form tetraploid mating products (Hull et al. 2000; Magee and Magee 2000; Alby et al. 2009). Mating in C. albicans is regulated by the white-opaque phenotypic switch. White cells can reversibly transition to the opaque state and only cells in the opaque state are competent for mating (Miller and Johnson 2002). In addition, the white-opaque switch is regulated by transcription factors encoded at the matingtype-like (MTL) locus, so that only a or $\alpha$ cells efficiently switch to the opaque state under standard growth conditions (Miller and Johnson 2002; Xie et al. 2013). Comparisons of diploid and tetraploid C. albicans cells showed that tetraploid strains display a modest defect in virulence compared to diploids (Ibrahim et al.2005).

Perhaps the most striking aspect of the $C$. albicans mating cycle is the apparent lack of a true meiosis. The C. albicans genome contains orthologs of many genes that are associated with meiosis in other species (Tzung et al. 2001), and yet meiosis has not been observed (Bennett and Johnson 2003). Indeed, the related species Candida lusitaniae is able to undergo meiosis despite having a more limited repertoire of "meiosis-specific" genes (Butler et al. 2009; Reedy et al. 2009). Recent studies revealed that mating and meiosis are coupled regulatory processes in C. lusitaniae, thereby promoting propagation in the haploid state (Sherwood et al. 2014). In place of meiosis, C. albicans tetraploid cells return to the diploid state via a parasexual program of concerted chromosome loss (Bennett and Johnson 2003). Thus, when cultured on certain media, tetraploids show genome instability, reducing their ploidy to that of a diploid, or near-diploid, cell. Genetic recombination between chromosome homologs is observed during chromosome loss, although the frequency of recombination is considerably lower than that during a conventional meiosis (Forche et al. 2008).

Multiple steps in the C. albicans parasexual cycle, including the white-to-opaque switch, sexual conjugation, and concerted chromosome loss, are stimulated by environmental stress or nutrient-poor conditions (Bennett and Johnson 2003; Ramírez-Zavala et al. 2008; Alby and Bennett 2009; Huang et al. 2009). This raises the possibility that parasex may act as a generator of genetic diversity precisely when adaptation to the environment is most beneficial (Berman and Hadany 2012). Recently, the related fungal pathogen Candida tropicalis was found to undergo a parasexual cycle similar to that in C. albicans. This includes white-opaque switching, efficient sexual conjugation between opaque cells, and concerted chromosome loss to achieve a diploid-tetraploid-diploid life cy- 
cle (Porman et al. 2011; Xie et al. 2012; Seervai et al. 2013).

In a surprising recent development, viable haploid forms of $C$. albicans were isolated from both in vitro and in vivo experiments (Hickman et al. 2013). Analysis by flow cytometry and comparative genome hybridization (CGH) confirmed that true haploid cells were formed that were monosomic for each of the eight chromosomes of C. albicans. Haploids were originally thought to be inviable because of the presence of recessive lethal alleles on multiple chromosomes. Although viable haploids exist, they show marked defects in fitness and virulence, presumably caused by loss of beneficial alleles from the heterozygous diploid. The formation of haploid cells appears to occur via parasexual chromosome loss rather than via meiosis, as haploid progeny showed few, if any, signatures of chromosome crossovers (Hickman et al. 2013). Haploids also spontaneously auto-diploidized and the resulting auto-diploids showed the same fitness defects as those of haploids, implying that decreased fitness was not a consequence of haploidy per se (Hickman et al. 2013). Despite their limited fitness, haploids showed phenotypic properties similar to those of diploid cells, including white-opaque switching, filamentation, chlamydospore formation, and mating. Thus, C. albicans haploids represent a potentially exciting tool for future genetic studies of the species.

\section{Meiosis versus Parasex}

What mechanistic differences distinguish fungal meiosis and parasex? Are these processes fundamentally different or are they variations on the same theme? And could there be advantages to undergoing parasex in place of meiosis? In this section, we compare the programs of meiosis and concerted chromosome loss and emphasize important differences between these two processes.

Several characteristics distinguish fungal meiosis from parasexual chromosome loss. First, meiosis is a complex developmental program, whereas parasex does not involve the same degree of complexity. For example, in
S. cerevisiae and S. pombe, signals from the mating locus, as well as environmental cues, converge onto the promoter of a master regulator of meiosis, Ime1 and Ste11, respectively (for reviews, see Sherwood and Bennett 2009; Neiman 2011; van Werven and Amon 2011). In contrast, parasexual chromosome loss in C. albicans and A. nidulans is mating-type locus independent, and there is no evidence for involvement of a master transcription factor (Bennett and Johnson 2003; Alby et al. 2009; Dyer and O'Gorman 2012).

Second, nutritional signals tightly regulate sexual programs, but not parasex, by controlling expression of the master transcriptional regulators. In both S. cerevisiae and S. pombe, nitrogen starvation promotes entry into meiosis, whereas the presence of glucose inhibits meiosis. In contrast, there is no evidence that defined nutritional signaling pathways activate parasexual chromosome loss, although environmental stress increases the frequency of chromosome loss in both C. albicans and C. tropicalis (Bennett and Johnson 2003; Alby and Bennett 2010; Berman and Hadany 2012; Seervai et al. 2013).

A third major difference between meiosis and parasex is that chromosome dynamics are highly coordinated during meiosis but are not obviously coordinated in parasex. Homologous chromosomes segregate during meiosis I, whereas sister chromatids split during meiosis II, such that meiosis II closely resembles a mitotic division. Coordinated movement of chromosomes has not been reported during parasex, and current models suggest that ploidy reduction occurs by chromosome nondisjunction, leading to an uneven segregation of chromosomes during cell division. Furthermore, in studies of parasex in A. nidulans, "haploidization" often is promoted by the addition of microtubule-destabilizing drugs to disrupt normal chromosome segregation (Schoustra et al. 2007). As a direct result of these processes, parasex often results in the formation of aneuploid progeny with varied phenotypes (Fig. 2, and discussed below).

Fourth, there is a marked difference between the levels of homologous recombination that occur during meiosis and parasex. In meiosis 
Fungal Ploidy and Parasexual Cycles

I, recombination between homologous chromosomes leads to high levels of meiotic recombinants (for detailed reviews, see Petronczki et al. 2003; Keeney and Neale 2006; Miller et al. 2013). Meiotic recombination is dependent on the processing of DNA double-strand breaks introduced by the conserved endodeoxyribonuclease, Spo11 (Keeney 2008). In S. cerevisiae, each meiotic progeny experiences 140-170 double-strand breaks per meiosis and all chromosomes experience at least one genetic crossover (Buhler et al. 2007; Mancera et al. 2008). In contrast, the frequency of mitotic recombination during parasex is significantly lower. In C. albicans, only a subset of parasexual progeny showed evidence of homologous recombination, and, even in these, progeny recombination events were limited to a small number of chromosomes (Forche et al. 2008). Similarly, in A. nidulans, mitotic segregation and recombination occurred at a lower level than that during conventional sexual reproduction (Pontecorvo et al. 1953b).

Fifth, many of the genes mediating meiotic recombination have been defined and are generally conserved in sexually reproducing species (Keeney et al. 1997; Keeney 2001; Villeneuve and Hillers 2001; Gerton and DeRisi 2002; Ramesh et al. 2005; Richard et al. 2005; Malik et al. 2008), but they are not required for parasexual chromosome loss. Thus, chromosome loss in C. albicans was not inhibited by the deletion of meiosis-specific genes such as $H O P 1$ or DLH1 (ortholog of DMC1) (Bennett and Johnson 2003). It should be noted, however, that some fungal species undergo meiosis despite the absence of orthologs considered to be a prerequisite for meiosis (Butler et al. 2009; Reedy et al. 2009). Curiously, Spo11, the conserved meiotic endodeoxyribonuclease, was shown to be required for parasexual recombination in C. albicans, but not for chromosome loss per se (Forche et al. 2008). The requirement of Spo11 for parasexual recombination suggests intriguing links between parasex and a conventional meiosis despite the significant mechanistic differences between these programs.

A further difference between meiosis and parasexual chromosome loss is the presence and absence of spore formation, respectively. Meiosis and sporulation are coupled processes in sexual fungi, ultimately yielding protective spores (Neiman 2011). Sexual spores have the potential to be highly antigenic, and the resulting immune response from the host could be detrimental to the pathogen (Nielsen and Heitman 2007). Interestingly, human-associated isolates of $S$. cerevisiae (including clinical isolates from immunocompromised patients) show a reduced frequency of sexual recombination relative to isolates from the environment (Magwene et al. 2011). This reduction in sexual activity could reduce the formation of spores and is also consistent with the hypothesis that sexual reproduction is disadvantageous for pathogens, as recombination may break up combinations of genes that are optimal for growth in the host (Nielsen and Heitman 2007).

\section{Endoreduplication and Mitotic Collapse}

Increases in fungal ploidy are often the result of conjugation between mating partners, yet ploidy increases also can occur by endoreduplication. In this process, replication of the DNA is uncoupled from mitotic division, resulting in an overall doubling of genome content. Endoreduplication has been observed in several human pathogens and provides an alternative mechanism for generating ploidy change and genotypic diversity (Fig. 2C) (Lee et al. 2009; Fox and Duronio 2013).

In $C$. albicans, classical studies showed that diploid strains could undergo spontaneous increases in ploidy, including the formation of triploid and tetraploid derivatives (Suzuki et al. 1982; Wickes and Petter 1996). Changes in ploidy were associated with accompanying differences in virulence (Suzuki et al. 1989). Also, as discussed earlier, in vitro passaging of C. albicans haploids can result in autodiploidization, a striking form of endoreduplication, to form homozygous diploids (Hickman et al. 2013).

In C. neoformans, a remarkable example of ploidy change via endoreduplication has been established. Populations of cells recovered from lung lavages included "titan" cells that were up 
R.J. Bennett et al.

to $100 \mu \mathrm{m}$ in diameter, far larger than the typical C. neoformans cell (Fig. 2C) (Zaragoza et al. 2010; Okagaki et al. 2011; Okagaki and Nielsen 2012). Titan cells also formed during coculture with macrophages or following treatment with host phospholipids, forming tetraploids, octaploids, and even higher ploidy cells with as many as 64 copies of the genome (Zaragoza et al. 2010; Chrisman et al. 2011; Garcia-Rodas et al. 2011; Okagaki et al. 2011; Okagaki and Nielsen 2012; Zaragoza and Nielsen 2013). The large size of $C$. neoformans titan cells precludes their phagocytosis by host immune cells, and these cells also are resistant to oxidative and nitrosative stress. Titan cells may promote the establishment of latent lung infections; subsequently, the generation of smaller cells with lower ploidy could facilitate dissemination to the central nervous system (Crabtree et al. 2011; Zaragoza and Nielsen 2013). Titan-cellderived daughter cells may include those with altered karyotypes, thereby further increasing the diversity of isolates that can disseminate through the body (Fig. 2C) (Morrow and Fraser 2013).

C. neoformans haploid cells can also form homotypic diploid cells by autodiploidization (Lin et al. 2005, 2009; Desnos-Ollivier et al. 2010). Autodiploidization can occur via either endoreduplication of the genome or self-mating of haploid cells (Lin et al. 2005). Although both processes are likely to occur in nature, one study showed that homotypic diploids formed during infection of a mouse were generated solely by endoreduplication and not by selffusion (Desnos-Ollivier et al. 2010). Whether autodiploidization observed during in vivo infection models is related to the much more striking ploidy changes observed in titan cells remains to be determined.

\section{ANEUPLOIDY}

Aneuploidy Is Driven by Rapid Gains and Losses of Chromosomes

Aneuploidy, the presence of unequal numbers of chromosomes, is a common occurrence in fungi and plays an important role in adapta- tion to environmental stress. Diploid organisms can undergo chromosome gains (trisomy or tetrasomy) as well as chromosome losses (monosomy) (Fig. 1). Haploid organisms become aneuploid by acquiring extra chromosomes (disomy) because all chromosomes carry essential genes, and, thus, chromosome loss events are lethal. Aneuploidy is thought to arise through chromosome missegregation caused by nondisjunction events, although endoreduplication of individual chromosomes also can give rise to aneuploidy.

Aneuploidy is surprisingly frequent in fungal species and can arise both in vitro and in vivo (Bouchonville et al. 2009; Forche et al. 2009). For example, many commonly used C. albicans strains, such as CAI-4 and WO-1, contain supernumerary chromosomes (SNCs) (Chibana et al. 2000; Chen et al. 2004; Selmecki et al. 2005; Rustchenko 2007). Aneuploidy can result in phenotypic changes in C. albicans (Suzuki et al. 1989; Rustchenko-Bulgac et al. 1990), as well as in natural S. cerevisiae isolates (Tan et al. 2013). Furthermore, whole-genome sequencing of clinical isolates revealed that a number of C. albicans strains contain SNCs (C Cuomo and RJ Bennett, pers. comm.), and in vivo passaging of strains through a mouse also induced aneuploid formation (Forche et al. 2009). A survey of fluconazole-resistant isolates found at least one aneuploid chromosome in 50\% of the isolates (Selmecki et al. 2006).

As a general rule, the acquisition of extra chromosomes in diploid fungi is far more frequent than chromosome loss, presumably because a $33 \%$ increase in gene dosage (from two copies to three copies) is better tolerated than a $50 \%$ decrease in gene dosage (from two copies to one copy) (Gresham et al. 2008; Pavelka et al. 2010; Tan et al. 2013). However, monosomy also is seen under selective growth conditions. In a classic example, growth of diploid C. albicans cells on sorbose medium results in the loss of one copy of chromosome 5 (Chr5) (Janbon et al. 1998, 1999). Subsequent growth on nutrientrich medium results in spontaneous endoreduplication of Chr5, indicating that removal from the selective environment results in reestablishment of the diploid state of Chr5. Perhaps of 
Fungal Ploidy and Parasexual Cycles

more relevance to the clinic, Chr5 monosomy also affected the response to several classes of antifungal drugs (Yang et al. 2013).

An important feature of aneuploidy is its potential transience. Extra chromosomes can arise rapidly and be lost rapidly, even within a single mitotic division. In general, cells that are aneuploid show reduced genome stability and are therefore more prone to further chromosomal changes, at least under replete growth conditions (Torres et al. 2008, 2010). As a result, aneuploidy is often lost and cells return to the euploid state if there is no selective pressure to maintain the aneuploidy (Selmecki et al. 2006, 2009a). An attractive model is that aneuploidy provides a rapid, albeit imprecise, solution for adaptation to stress, thereby allowing cells to evolve more elegant solutions with a lower cost-to-benefit ratio. This was recently shown in a series of evolution experiments using chronic temperature stress in haploid S. cerevisiae cells (Yona et al. 2012). In this case, Chr3 disomy initially conferred improved growth at elevated temperatures, although point mutations eventually accumulated and aneuploidy was lost, presumably because the fitness cost of aneuploidy became higher than the associated advantage. Thus, under stress conditions, aneuploidy can provide a transient fix that promotes survival until a more refined (and lower cost) solution can be acquired.

Aneuploidy has the potential not only to diversify population phenotypes and promote adaptation, but also to drive additional genomic change, especially in cells exposed to stresses that threaten survival (Rancati et al. 2008). In haploid S. cerevisiae strains, aneuploidy increased rates of chromosome loss, genetic mutation, and microsatellite instability (Sheltzer and Amon 2011; Sheltzer et al. 2011). Importantly, although aneuploid cells generally showed elevated rates of genomic change, not all aneuploidies were equal, and elevated levels of noncoding DNA did not cause the same changes. This implies that excess copies of specific proteins, especially those in protein complexes sensitive to imbalanced stoichiometry, are primarily responsible for driving genotypic instability (Torres et al. 2008).

\section{Mechanisms that Generate Aneuploidy}

Both conventional sexual and parasexual cycles can generate extensive karyotypic diversity, including aneuploidy. In C. neoformans, Heitman and coworkers recently established that meiotic products from either bisexual $\mathbf{a}-\alpha$ mating or unisexual $\alpha-\alpha$ mating showed a wide range of phenotypes, and these phenotypes correlated with aneuploid chromosomes (Ni et al. 2013). Specifically, in unisexual $\alpha-\alpha$ matings, six out of 90 meiotic progeny $(\sim 7 \%)$ showed phenotypic changes, with four of the six progeny being aneuploid, each harboring an extra copy of chromosomes 9, 10, or 13 (Ni et al. 2013). Loss of the aneuploid chromosome restored euploidy and the parental phenotype. These experiments establish that unisexual mating between identical cells can generate phenotypic and genotypic diversity de novo, and this variation is often a direct consequence of karyotypic change (Ni et al. 2013).

Both C. neoformans and Cryptococcus gatti are typically haploid species that include multiple serotypes; $C$. neoformans includes serotypes A and D, whereas C. gattii consists of serotypes $B$ and $C$. In addition, a variety of natural hybrids have been reported, including both intervarietal hybrids (AA and $\mathrm{AD}$ ) and interspecies hybrids (AB and BD) (Tanaka et al. 1996; Cogliati et al. 2001; Lengeler et al. 2001; Bovers et al. 2006, 2008a,b; Lin et al. 2009). Most AD hybrids are diploid, whereas others show ploidies intermediate between $1 \mathrm{~N}$ and $2 \mathrm{~N}$ (Cogliati et al. 2001). Aneuploidy in AD hybrids is thought to be the consequence of missegregation during meiosis attributable to sequence differences $(10 \%-15 \%$ at the nucleotide level) between $\mathrm{A}$ and D strains (Lengeler et al. 2001; Kavanaugh et al. 2006). CGH analysis of the genomes of A, $\mathrm{D}$, and $\mathrm{AD}$ strains showed extensive variation, including regions of divergence, deletions, and amplifications. This included the unexpected amplification of Chr1 in two serotype A haploid strains ( $\mathrm{Hu}$ et al. 2008; Sun and $\mathrm{Xu}$ 2009). In addition, $\mathrm{AD}$ hybrids were generally less virulent than either A or D haploid strains (Cogliati et al. 2012). Together, these observations establish that the C. neoformans genome exists in a 
number of different configurations, including different aneuploid states.

In the emerging pathogen C. lusitaniae, a haploid-diploid-haploid sexual cycle culminates in meiosis and sporulation, yet $\sim 22 \%$ of the meiotic progeny remain diploid and $6 \%$ are aneuploid (Butler et al. 2009; Reedy et al. 2009). The level of aneuploidy and unconventional divisions seen in fungi may be more common in higher organisms than originally thought. For example, $7 \%-35 \%$ of human oocytes show aneuploidy (Hunt and Hassold 2008). In this case, aneuploidy is associated with detrimental consequences, including miscarriage and birth defects. In contrast, human liver and nerve cells often become polyploid or aneuploid without negative consequences. Presumably, this difference is explained by the fact that the process of embryonic development is exquisitely, sensitive to imbalances in gene products, whereas certain somatic tissues can benefit from the genetic diversity and adaptive potential of aneuploidy (Duncan 2013).

High levels of aneuploidy also can arise as a consequence of the parasexual cycle. In $C$. albicans, parasexual progeny frequently show aneuploidy, including strains carrying multiple SNCs. Thus, even when selected to be disomic for one chromosome, approximately two-thirds of progeny were aneuploid (Forche et al. 2008). Extensive phenotypic diversity also was observed, which is consistent with the idea that aneuploidy drives large-scale phenotypic changes (Rustchenko 2007; Forche et al. 2008; Rancati et al. 2008).

Finally, aneuploidy in fungi, as well as in somatic mammalian cells, can arise through defects in mitosis. In C. albicans, recent work suggests that exposure to fluconazole causes cells to uncouple nuclear and cell division, yielding an unusual cell type termed a "trimera." Trimeras are composed of three interconnected cells: mother, daughter, and granddaughter, with associated cell-cycle defects (Harrison et al. 2014). During trimera formation, two nuclei (from mother and daughter) replicate and divide, yielding four daughter nuclei within three cell compartments. One of the cells inherits two spindle pole bodies and two nuclei, becoming tetraploid, but with an extra mitotic spindle. The resulting multinucleate cells are often unstable and yield aneuploid progeny via defective chromosome segregation. This novel cell cycle occurs with high frequency in the presence of fluconazole ( $\sim 22 \%$ of cells) and may occur at lower frequency under other growth conditions. This phenomenon is reminiscent of the "ploidy conveyor" mechanism used by normal liver cells to cycle between diploid, polyploid, and aneuploid states (Duncan 2013), and a similar process may be responsible for aneuploidy in cancer cells (Ganem et al. 2007; Davoli et al. 2010; Davoli and de Lange 2011).

In summary, it is evident that high levels of genetic diversity can be introduced into a population via aneuploidy generated by mitosis, sexual reproduction, or the parasexual life cycle. This can occur even in the absence of interbreeding between different parent cells or homologous recombination between chromosomes. Therefore, we propose that aneuploid formation is the norm, rather than the exception, for fungal populations, with frequent karyotypic changes occurring in a subpopulation of cells. Furthermore, aneuploidy is likely to be common in certain mammalian somatic tissues as well.

\section{The Consequences of Aneuploidy}

In many species, aneuploidy is directly associated with marked phenotypic changes, and experiments have begun to address the molecular mechanisms underlying these differences. Aneuploid strains often, but not always, show slower growth, and this can be caused by the unbalanced protein stoichiometry resulting from gene expression from the aneuploid chromosome. Unlike sex chromosomes in which gene dosage compensation mechanisms regulate expression across the chromosome (Straub and Becker 2007), expression of most (but not necessarily all) encoded proteins typically scales with their gene copy number, at least in S. cerevisiae (Pavelka et al. 2010; Springer et al. 2010; Torres et al. 2010). This imbalance could be particularly critical for proteins that are part of multisubunit complexes, in which stoichiome- 
try is important for proper complex assembly and/or function (Torres et al. 2010). The resulting "aneuploidy stress response" can cause cells to attempt to restore normal protein stoichiometries by changes in protein degradation (Torres et al. 2008). In support of this model, mutations in the Ubp6 deubiquitinating enzyme improved the growth rates of some aneuploid strains because of increased clearance of excess proteins (Torres et al. 2010). Not all aneuploidies cause a reduction in growth rate (Selmecki et al. 2008, 2009a; Torres et al. 2008; Zhu et al. 2012), suggesting that fitness defects in aneuploids are not caused by the aneuploid state per se, but rather are a result of stoichiometric changes in specific proteins that are out of balance. Other factors likely to contribute to fitness defects include the higher demands associated with DNA replication and difficulty in segregating aneuploid chromosomes. This has been shown by "ploidy-specific lethality," as defects in factors associated with DNA repair, sister chromatid cohesion, or mitotic spindle function lead to lethality in S. cerevisiae tetraploids, but not in cells of lower ploidy (Storchova et al. 2006).

Although the detrimental effects of aneuploidy on fungal growth are often evident under replete culture conditions, aneuploid chromosomes can provide significant fitness advantages under suboptimal growth conditions (Fig. 1) (Rancati et al. 2008; Pavelka et al. 2010; Ni et al. 2013). Early studies in Candida glabrata showed that a fluconazole-resistant strain carried an extra copy of the chromosome containing ERG11, which encodes the target of fluconazole (vanden Bossche et al. 1992; Marichal et al. 1997). Aneuploidy also provided a growth advantage to $C$. albicans cells on sorbose medium, as Chr5 monosomy conferred improved growth on this medium and Chr5 reduplication reversed this phenotype (Janbon et al. 1998, 1999). In this case, sorbose use requires expression of the C. albicans SOU1 gene on Chr4, and it appears that multiple negative regulators of SOU1 expression are spaced along Chr5 (Kabir et al. 2005). Thus, loss of Chr5 facilitates SOU1 expression and provides a remarkable example in which, essentially, a whole chromosome is acting as a single regulatory unit.
An association between aneuploidy and fluconazole resistance also was suggested by studies in C. albicans, in which high levels of the drug yielded strains with different aneuploidies (Perepnikhatka et al. 1999). Analysis of multiple clinical isolates by CGH revealed a direct connection between drug resistance and the presence of isochromosome 5L (i $5 \mathrm{~L})$ ) (Selmecki et al. 2006). The isochromosome consisted of the two left arms of Chr5, and contained the ERG11 and TAC1 genes, encoding the target of fluconazole and a transcriptional regulator of drug efflux pumps, respectively. Loss of $\mathrm{i}(5 \mathrm{~L})$ during nonselective growth led to loss of the drug resistance phenotype, showing that the isochromosome was responsible for resistance (Selmecki et al. 2006). Furthermore, the increased copy number of ERG11 and TAC1 was sufficient to explain the levels of azole resistance conferred by i(5L) (Selmecki et al. 2006, 2008, 2009b).

In C. neoformans, a similar mechanism of drug resistance has been uncovered. Here, aneuploid chromosomes were associated with the phenomenon of "heteroresistance," in which a subpopulation of cells acquired reversible resistance to fluconazole (Mondon et al. 1999; Ngamskulrungroj et al. 2012a,b). Treatment of haploid C. neoformans cells with fluconazole resulted in disomy of up to four chromosomes (Chrs 1, 4, 10, and 14) (Sionov et al. 2009, 2010). Chrl disomy was common to all resistant isolates and included the genes encoding Erg11 and the major azole transporter, Afr1 (Sionov et al. 2010). Genes on Chr4 also were linked to drug resistance. These encode a GTPase and two GTPase-activating proteins that are involved in the regulation of endoplasmic reticulum morphogenesis and trafficking (Ngamskulrungroj et al. 2012b). The endoplasmic reticulum is a site for sterol synthesis, but the mechanism(s) by which these genes increase drug resistance is not known.

In S. cerevisiae, haploid strains have been engineered to be aneuploid by either the introduction of specific disomic chromosomes (Torres et al. 2010) or induction of meiosis in triploid cells (Pavelka et al. 2010). Importantly, when exposed to a range of stress conditions, most aneuploid isolates showed a growth advantage under at least one stress condition (Pavelka 
R.J. Bennett et al.

et al. 2010; Chen et al. 2012; Zhu et al. 2012). These studies concluded that different combinations of chromosomes could provide a selective advantage in the face of conditions that stress euploid cells. A study of natural S. cerevisiae isolates found that aneuploidy could result in a semistable colony phenotype involving filamentous growth (Tan et al. 2013). Interestingly, several different chromosomes, when aneuploid, could confer a similar colony phenotype (Tan et al. 2013).

A recent study uncovered an interesting link between apoptosis and the tolerance of aneuploid chromosomes. In C. neoformans, the conserved AIF1 gene encodes apoptosis-inducing factor and is involved in promoting apoptosislike cell death (Hamann et al. 2008). Deletion of AIF1 potentiated adaptation to fluconazole caused by decreased apoptosis and increased tolerance of aneuploid chromosomes (Semighini et al. 2011). Significantly, clinical C. neoformans isolates were found to show varied AIF1 expression. For example, one isolate showed high levels of heteroresistance to fluconazole and stable Chrl aneuploidy, and these characteristics were a consequence of decreased AIF1 expression (Semighini et al. 2011). Thus, regulation of apoptosis-like pathways can modulate aneuploid formation and associated drug resistance in pathogens such as C. neoformans.

Aneuploid formation in fungi also can be influenced by molecular chaperone activities. Inhibition of Hsp90 resulted in increased chromosome instability and aneuploid formation in S. cerevisiae (Chen et al. 2012). Furthermore, the karyotypic changes induced by Hsp90 inhibition increased adaptation to other unrelated forms of cellular stress. This is consistent with the stress-induced mutagenesis model (Galhardo et al. 2007), in which aneuploidy promotes formation of a pool of karyotypic variants that then have the potential to enhance adaptation to additional, diverse perturbations (Rancati et al. 2008; Chen et al. 2012).

\section{Loss of Heterozygosity}

$\mathrm{LOH}$ has emerged as a major mechanism to generate genetic diversity in populations of heterozygous organisms. This is relevant for $C$. albicans, which is normally found as a highly heterozygous diploid (Butler et al. 2009), as well as for hybrid forms of Cryptococcus (Cogliati et al. 2001; Lengeler et al. 2001; Lin et al. 2008; Li et al. 2012; Ni et al. 2013). Homozygosis of short genomic regions (usually $<2 \mathrm{~kb}$ ) can arise by recombination via gene conversion or double-chromosome crossovers. Long-range $\mathrm{LOH}$ is attributable to either single crossovers with segregation of opposite alleles away from each other, or break-induced replication (BIR), in which a DNA break is repaired by strand invasion and replication fork progression (Fig. 3). As a result, long-range $\mathrm{LOH}$ events are homozygous from the site of the DNA break to the end of the chromosome (for reviews of BIR, see Kraus et al. 2001; Llorente et al. 2008). Whole-chromosome $\mathrm{LOH}$ can result from chromosome loss caused by nondisjunction followed by reduplication of the remaining homolog (Fig. 3). Alternatively, whole-chromosome $\mathrm{LOH}$ can result from chromosome gain followed by loss of the heterozygous homolog (e.g., nondisjunction could first yield a segregant with a trisomic "aab" configuration, and subsequent loss of homolog b would generate a homozygous "aa" cell, as shown in Fig. 3).

Similar to ploidy shifts, $\mathrm{LOH}$ can arise rapidly in a single cell cycle. However, once $\mathrm{LOH}$ occurs, it is irreversible, unless the cell outcrosses to regain the lost heterozygous alleles. In $C$. albicans, the opportunity for outcrossing while in the host is likely to be limited (Ramírez-Zavala et al. 2008; Morschhäuser 2010; Xie et al. 2013). Thus, tracts of $\mathrm{LOH}$ are often shared among related progeny within a given host, and they also can be traced in laboratory-derived strain lineages (Abbey et al. 2011). A detailed analysis of $\mathrm{LOH}$ showed that most C. albicans isolates have at least one $\mathrm{LOH}$ tract, usually of the "long-range $\mathrm{LOH}$ " type (Jones et al. 2004; Butler et al. 2009; C Cuomo and RJ Bennett, pers. comm.). For example, strain SC5314 is homozygous for both distal ends of ChrR, most of Chr3R, as well as large regions of both arms of Chr7 (Jones et al. 2004), whereas strain WO-1 has at least one long-range $\mathrm{LOH}$ tract on each chromosome (Butler et al. 2009). 
Fungal Ploidy and Parasexual Cycles

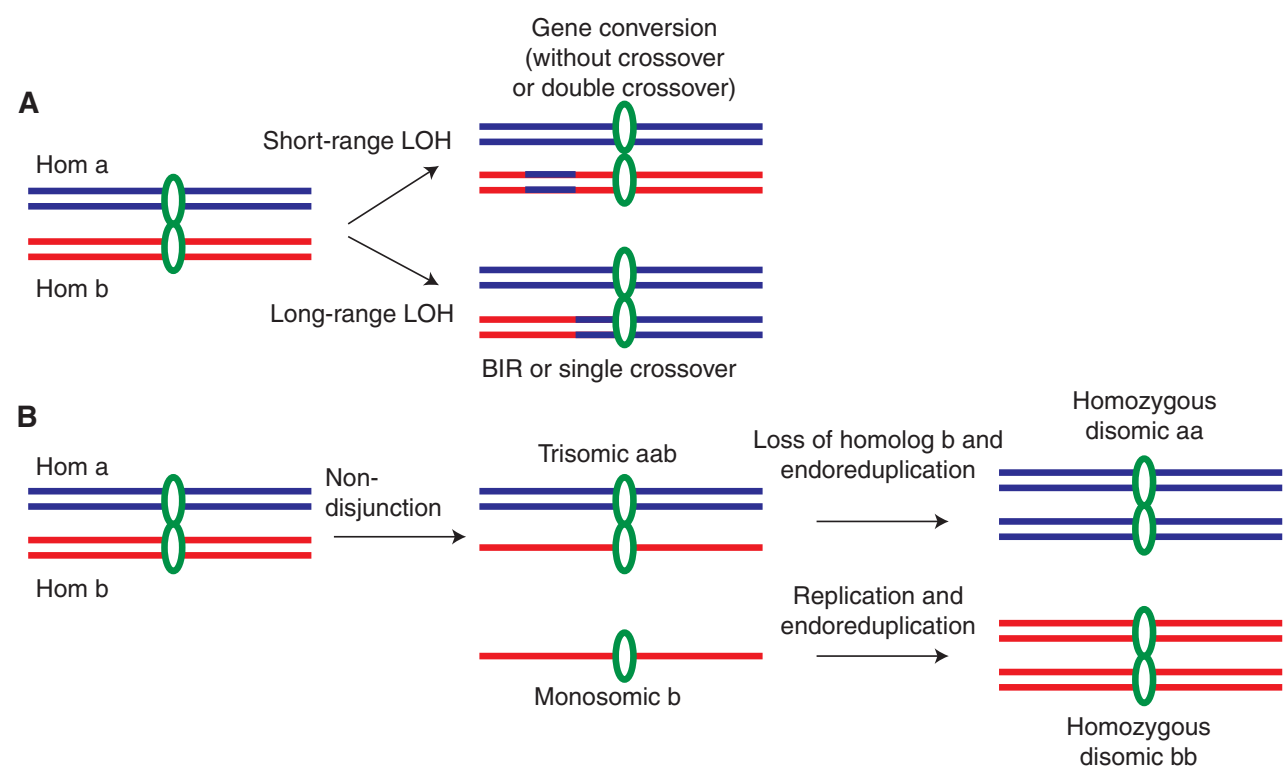

Figure 3. LOH via recombination and chromosome nondisjunction in a heterozygous diploid organism. $(A)$ Recombination can generate short-range $\mathrm{LOH}$ events by gene conversion or double crossovers. Long-range $\mathrm{LOH}$ events are caused by BIR or single crossovers. (B) Nondisjunction/chromosome missegregation events can generate whole-chromosome LOH. Nondisjunction can yield trisomic or monosomic progeny. Whole-chromosome $\mathrm{LOH}$ then arises by either missegregation of the heterozygous homolog in the trisomic individual or endoreduplication of the hemizygous homolog (hom).

Multiple processes can affect $\mathrm{LOH}$ rates and types in C. albicans. For example, the frequency of LOH is enhanced by passage through a murine host (Forche et al.2009), indicating that it occurs in response to in vivo signals. In vitro studies show that environmental stress also increases LOH; exposure to oxidative stress, febrile temperature, or an antifungal drug all increased LOH in derivatives of strain SC5314 (Forche et al. 2011). Oxidative stress increased the proportion of short-range $\mathrm{LOH}$, whereas high temperatures or exposure to fluconazole increased the proportion of whole-chromosome LOH. This presumably reflects the nature of different stresses; oxidative stress introduces DNA breaks that must be resolved via recombination, whereas heat shock and fluconazole presumably show a stronger effect on chromosome-segregation mechanisms. Whole-chromosome $\mathrm{LOH}$ also was prevalent in parasexual progeny (Bennett and Johnson 2003; Forche et al. 2008) and could be a consequence of the stress conditions used to induce concerted chromosome loss.
LOH represents the loss of genetic information, yet it can lead to phenotypic variation at the population level attributable to differences between heterozygous alleles. Phenotypes resulting from $\mathrm{LOH}$ can have a profound effect on clinically relevant traits, including increased drug resistance. In C. albicans, resistance can be altered because of LOH of TAC1, which encodes a transcription factor that up-regulates the $\mathrm{ABC}$-transporter genes $C D R 1$ and $C D R 2$ (Coste et al. 2006), and MRR1, which encodes a transcription factor that regulates expression of the Mdr1 multidrug-resistance transporter (Dunkel et al. 2008). For both TAC1 and MRR1, hyperactive mutant alleles that increase expression of the corresponding transporters exist, and homozygosis of these alleles, therefore, increases drug resistance. LOH after the acquisition of a point mutation also was detected at ERG11 (White 1997), which is the direct target of fluconazole, and UPC2, which encodes a transcription factor that up-regulates ERG11 expression (Heilmann et al. 2010). Thus, LOH 
R.J. Bennett et al.

of mutant alleles appears to be a common mechanism by which strains can acquire stable drug resistance.

As discussed earlier, the diploid state of C. albicans was originally thought to be obligate because of recessive lethal alleles dispersed across the heterozygous genome. However, cells containing homozygous chromosomes (Bennett and Johnson 2003; Forche et al. 2008; Zörgö et al. 2013), and the subsequent identification of true haploid forms (Hickman et al. 2013), showed that C. albicans cells could tolerate homozygosity on all eight chromosomes. Nonetheless, a conspicuous bias for homozygosity was observed for several homologs, suggesting that lethal recessive alleles do exist on some homologs (i.e., alleles on homologs that were not recovered). Haploid isolates all showed reduced fitness, implying that alleles that result in suboptimal growth are present on the recovered homologs (Hickman et al. 2013). Consistent with this, the fitness of diploid strains decreased in proportion to their homozygosity, with strains carrying longer LOH tracts generally having slower growth rates (Abbey et al. 2011). Furthermore, the level of heterozygosity in clinical isolates of $C$. albicans correlates with the ability to cause disease in an invertebrate host (C Cuomo and RJ Bennett, pers. comm.). Therefore, it is likely that heterozygosity, at least when averaged across the whole genome, is an important virulence trait in this species.

In theory, different alleles can confer distinct phenotypes because of amino acid differences in the encoded protein, as seen with TAC1 and $M R R 1$, or because of changes in expression levels between alleles (Staib et al. 2002; Holmes et al. 2006; Sanz et al. 2007). A recent study used a phased diploid sequence assembly to analyze C. albicans RNAseq data (Bruno et al. 2010) and found that alleles were differentially expressed in 3.6\% of the genes (Muzzey et al. 2013). Thus, at least for C. albicans, $\mathrm{LOH}$ can result in altered phenotypes based on changes in gene expression levels as well as changes in the encoded proteins.

LOH has been similarly documented in AD hybrids of $C$. neoformans, which are highly dy- namic and undergo extensive chromosome loss, often followed by reduplication of the remaining homolog (Li et al. 2012). AD hybrids showed hybrid vigor (heterosis), adapting to changing environments better than either A or $\mathrm{D}$ isolates ( $\mathrm{Li}$ et al. 2012). Furthermore, extensive $\mathrm{LOH}$ in $\mathrm{AD}$ hybrid strains resulted in preferential retention of the serotype A homolog of Chr1 (Hu et al. 2008), which may contribute to a selective advantage in the mammalian host (Kwon-Chung and Bennett 1984; Irokanulo and Akueshi 1995; Lin et al. 2008). This provides an example of how $\mathrm{LOH}$ has the potential to confer adaptive benefits under selective pressure.

\section{SUMMARY}

In general, human fungal pathogens show considerable genome plasticity and can generate diversity through unconventional mechanisms. Many possess specialized sexual or parasexual life cycles that are unusual when compared with model species. These differences include the phenomena of white-opaque switching in C. albicans, and modes of same-sex mating in both C. albicans and C. neoformans. Mitosis can also drive large-scale karyotypic changes, including endoreduplication, trimera cell formation, concerted chromosome loss, and $\mathrm{LOH}$. The consequences of these genomic changes are nontrivial and include the frequent emergence of drug-resistant strains in the clinic. Whether it is the stress encountered during growth in a mammalian host, or other factors that led to these unusual mechanisms of genome diversification, remains to be seen. What is clear, however, is that analogous mechanisms of genome change occur in mammalian tissues, suggesting that these processes are more widespread than previously considered. Advances in our understanding of genome plasticity will be key to the appropriate understanding, treatment, and prevention of fungal infections.

\section{REFERENCES}

\footnotetext{
Abbey D, Hickman M, Gresham D, Berman J. 2011. Highresolution SNP/CGH microarrays reveal the accumulation of loss of heterozygosity in commonly used Candida albicans strains. G3 (Bethesda) 1: 523-530.
} 
Alby K, Bennett RJ. 2009. Stress-induced phenotypic switching in Candida albicans. Mol Biol Cell 20: 31783191.

Alby K, Bennett R. 2010. Sexual reproduction in the Candida clade: Cryptic cycles, diverse mechanisms, and alternative functions. Cell Mol Life Sci 67: 3275-3285.

Alby K, Schaefer D, Bennett RJ. 2009. Homothallic and heterothallic mating in the opportunistic pathogen Candida albicans. Nature 460: 890-893.

Bennett RJ, Johnson AD. 2003. Completion of a parasexual cycle in Candida albicans by induced chromosome loss in tetraploid strains. Embo J 22: 2505-2515.

Bennett RJ, Miller MG, Chua PR, Maxon ME, Johnson AD. 2005. Nuclear fusion occurs during mating in Candida albicans and is dependent on the KAR3 gene. Mol Microbiol 55: 1046-1059.

Berg CM, Garber ED. 1962. A genetic analysis of color mutants of Aspergillus fumigatus. Genetics 47: 1139-1146.

Berman J. 2010. Evolutionary genomics: When abnormality is beneficial. Nature 468: 183-184.

Berman J, Hadany L. 2012. Does stress induce (para)sex? Implications for Candida albicans evolution. Trends Genet 28: $197-203$

Bouchonville K, Forche A, Tang KE, Selmecki A, Berman J. 2009. Aneuploid chromosomes are highly unstable during DNA transformation of Candida albicans. Eukaryot Cell 8: 1554-1566.

Bovers M, Hagen F, Kuramae EE, Diaz MR, Spanjaard L, Dromer F, Hoogveld HL, Boekhout T. 2006. Unique hybrids between the fungal pathogens Cryptococcus neoformans and Cryptococcus gattii. FEMS Yeast Res 6: 599-607.

Bovers M, Hagen F, Kuramae EE, Boekhout T. 2008a. Six monophyletic lineages identified within Cryptococcus neoformans and Cryptococcus gattii by multi-locus sequence typing. Fung Genet Biol 45: 400-421.

Bovers M, Hagen F, Kuramae EE, Hoogveld HL, Dromer F St-Germain G, Boekhout T. 2008b. AIDS patient death caused by novel Cryptococcus neoformans x C. gattii hybrid. Emerg Infect Dis 14: 1105-1108.

Bruno VM, Wang Z, Marjani SL, Euskirchen GM, Martin J, Sherlock G, Snyder M. 2010. Comprehensive annotation of the transcriptome of the human fungal pathogen $\mathrm{Can}$ dida albicans using RNA-seq. Genome Res 20: 14511458.

Buhler C, Borde V, Lichten M. 2007. Mapping meiotic single-strand DNA reveals a new landscape of DNA doublestrand breaks in Saccharomyces cerevisiae. PLoS Biol 5: e324.

Butler G, Rasmussen MD, Lin MF, Santos MAS, Sakthikumar S, Munro CA, Rheinbay E, Grabherr M, Forche A, Reedy JL, et al. 2009. Evolution of pathogenicity and sexual reproduction in eight Candida genomes. Nature 459: 657-662.

Casadevall A, Perfect JR. 1998. Cryptococcus neoformans. ASM, Washington, DC.

Chen X, Magee BB, Dawson D, Magee PT, Kumamoto CA. 2004. Chromosome 1 trisomy compromises the virulence of Candida albicans. Mol Microbiol 51: 551-565.

Chen G, Bradford WD, Seidel CW, Li R. 2012. Hsp90 stress potentiates rapid cellular adaptation through induction of aneuploidy. Nature 482: 246-250.
Chibana H, Beckerman JL, Magee PT. 2000. Fine-resolution physical mapping of genomic diversity in Candida albicans. Genome Res 10: 1865-1877.

Chrisman CJ, Albuquerque P, Guimaraes AJ, Nieves E, Casadevall A. 2011. Phospholipids trigger Cryptococcus neoformans capsular enlargement during interactions with amoebae and macrophages. PLoS Pathog 7: e1002047.

Cogliati M, Esposto MC, Clarke DL, Wickes BL, Viviani MA. 2001. Origin of Cryptococcus neoformansvar. neoformans diploid strains. J Clin Microbiol 39: 3889-3894.

Cogliati M, Barchiesi F, Spreghini E, Tortorano AM. 2012. Heterozygosis and pathogenicity of Cryptococcus neoformans AD-hybrid isolates. Mycopathologia 173: 347-357.

Coste A, Turner V, Ischer F, Morschhäuser J, Forche A, Selmecki A, Berman J, Bille J, Sanglard D. 2006. A mutation in Taclp, a transcription factor regulating CDR1 and $C D R 2$, is coupled with loss of heterozygosity at chromosome 5 to mediate antifungal resistance in Candida albicans. Genetics 172: 2139-2156.

Crabtree JN, Okagaki LH, Wiesner DL, Strain AK, Nielsen JN, Nielsen K. 2011. Titan cell production enhances the virulence of Cryptococcus neoformans. Infect Immun 80: 3776-3785.

Davoli T, de Lange T. 2011. The causes and consequences of polyploidy in normal development and cancer. Annu Rev Cell Dev Biol 27: 585-610.

Davoli T, Denchi EL, De Lange T. 2010. Persistent telomere damage induces bypass of mitotis and tetraploidy. Cell 141: 81-93.

Desnos-Ollivier M, Patel S, Spaulding AR, Charlier C, Garcia-Hermoso D, Nielsen K, Dromer F. 2010. Mixed infections and in vivo evolution in the human fungal pathogen Cryptococcus neoformans. MBio 1: e00091-10.

Duncan AW. 2013. Aneuploidy, polyploidy and ploidy reversal in the liver. Semin Cell Dev Biol 24: 347-356.

Duncan AW, Hanlon Newell AE, Bi W, Finegold MJ, Olson SB, Beaudet AL, Grompe M. 2012. Aneuploidy as a mechanism for stress-induced liver adaptation. J Clin Invest 122: 3307-3315.

Dunkel N, Blaß J, Rogers PD, Morschhäuser J. 2008. Mutations in the multi-drug resistance regulator MRR1, followed by loss of heterozygosity, are the main cause of MDR1 overexpression in fluconazole-resistant Candida albicans strains. Mol Microbiol 69: 827-840.

Dyer PS, O'Gorman CM. 2012. Sexual development and cryptic sexuality in fungi: Insights from Aspergillus species. FEMS Microbiol Rev 36: 165-192.

Ene IV, Bennett RJ. 2014. The cryptic sexual strategies of human fungal pathogens. Nat Rev Microbiol 12: 239_ 251.

Forche A, Alby K, Schaefer D, Johnson AD, Berman J, Bennett RJ. 2008. The parasexual cycle in Candida albicans provides an alternative pathway to meiosis for the formation of recombinant strains. PLoS Biol 6: e110.

Forche A, Magee PT, Selmecki A, Berman J, May G. 2009 Evolution in Candida albicans populations during single passage through a mouse host. Genetics 182: 799-811.

Forche A, Abbey D, Pisithkul T, Weinzierl MA, Ringstrom T, Bruck D, Petersen K, Berman J. 2011. Stress alters rates and types of loss of heterozygosity in Candida albicans. MBio 2: e00129-11. 


\section{R.J. Bennett et al.}

Fox DT, Duronio RJ. 2013. Endoreplication and polyploidy: Insights into development and disease. Development 140: $3-12$.

Fraser JA, Huang JC, Pukkila-Worley R, Alspaugh JA, Mitchell TG, Heitman J. 2005. Chromosomal translocation and segmental duplication in Cryptococcus neoformans. Eukaryot Cell 4: 401-406.

Galgoczy DJ, Cassidy-Stone A, Llinas M, O’Rourke SM, Herskowitz I, DeRisi JL, Johnson AD. 2004. Genomic dissection of the cell-type-specification circuit in Saccharomyces cerevisiae. Proc Natl Acad Sci 101: 18069-18074.

Galhardo RS, Hastings PJ, Rosenberg SM. 2007. Mutation as a stress response and the regulation of evolvability. Crit Rev Biochem Mol Biol 42: 399-435.

Galitski T, Saldanha AJ, Styles CA, Lander ES, Fink GR 1999. Ploidy regulation of gene expression. Science 285: 251-254.

Ganem NJ, Storchova Z, Pellman D. 2007. Tetraploidy, aneuploidy and cancer. Curr Opin Genet Dev 17: 157-162.

Garcia-Rodas R, Casadevall A, Rodriguez-Tudela JL, Cuenca-Estrella M, Zaragoza O. 2011. Cryptococcus neoformans capsular enlargement and cellular gigantism during Galleria mellonella infection. PLoS ONE 6: e24485.

Geiser DM, Pitt JI, Taylor JW. 1998. Cryptic speciation and recombination in the aflatoxin-producing fungus Aspergillus flavus. Proc Natl Acad Sci 95: 388-393.

Gerstein AC, Otto SP. 2009. Ploidy and the causes of genomic evolution. J Heredity 100: 571-581.

Gerstein AC, Chun H-JE, Grant A, Otto SP. 2006. Genomic convergence toward diploidy in Saccharomyces cerevisiae. PLoS Genet 2: e145.

Gerton JL, DeRisi JL. 2002. Mnd1p: An evolutionarily conserved protein required for meiotic recombination. Proc Natl Acad Sci 99: 6895-6900.

Gresham D, Desai MM, Tucker CM, Jenq HT, Pai DA, Ward A, DeSevo CG, Botstein D, Dunham MJ. 2008. The repertoire and dynamics of evolutionary adaptations to controlled nutrient-limited environments in yeast. PLoS Genet 4: e1000303.

Hamann A, Brust D, Osiewacz HD. 2008. Apoptosis pathways in fungal growth, development and ageing. Trends Microbiol 16: 276-283.

Harrison BD, Hashemi J, Bibi M, Pulver R, Bavli D, Nahmias Y, Wellington M, Sapiro G, Berman J. 2014. A tetraploid intermediate precedes aneuploid formation in yeasts $\mathrm{ex}$ posed to fluconazole. PLoS Biol 12: e1001815.

Heilmann CJ, Schneider S, Barker KS, Rogers PD, Morschhäuser J. 2010. An A643T mutation in the transcription factor Upc2p causes constitutive ERG11 upregulation and increased fluconazole resistance in Candida albicans. Antimicrob Agents Chemother 54: 353-359.

Hickman M, Zeng G, Forche A, Hirakawa MP, Abbey D, Harrison BD, Wang YM, Su CH, Bennett RJ, Wang Y, et al. 2013. The "obligate diploid" Candida albicans forms mating-competent haploids. Nature 494: 55-59.

Holmes AR, Tsao S, Ong SW, Lamping E, Niimi K, Monk BC, Niimi M, Kaneko A, Holland BR, Schmid J, et al. 2006. Heterozygosity and functional allelic variation in the Candida albicans efflux pump genes CDR1 and CDR2. Mol Microbiol 62: 170-186.
Hu G, Liu I, Sham A, Stajich JE, Dietrich FS, Kronstad JW. 2008. Comparative hybridization reveals extensive genome variation in the AIDS-associated pathogen Cryptococcus neoformans. Genome Biol 9: R41.

Huang G, Srikantha T, Sahni N, Yi S, Soll DR. 2009. $\mathrm{CO}_{2}$ regulates white-to-opaque switching in Candida albicans. Curr Biol 19: 330-334.

Hull CM, Johnson AD. 1999. Identification of a mating type-like locus in the asexual pathogenic yeast Candida albicans. Science 285: 1271-1275.

Hull CM, Raisner RM, Johnson AD. 2000. Evidence for mating of the "asexual" yeast Candida albicans in a mammalian host. Science 289: 307-310.

Hull CM, Davidson RC, Heitman J. 2002. Cell identity and sexual development in Cryptococcus neoformans are controlled by the mating-type-specific homeodomain protein Sxil $\alpha$. Genes Dev 16: 3046-3060.

Hull CM, Boily MJ, Heitman J. 2005. Sex-specific homeodomain proteins Sxil $\alpha$ and Sxi2a coordinately regulate sexual development in Cryptococcus neoformans. Eukaryot Cell 4: 526-535.

Hunt PA, Hassold TJ. 2008. Human female meiosis: What makes a good egg go bad? Trends Genet 24: 86-93.

Ibrahim AS, Magee BB, Sheppard DC, Yang M, Kauffman S, Becker J, Edwards JE Jr, Magee PT. 2005. Effects of ploidy and mating type on virulence of Candida albicans. Infect Immun 73: 7366-7374.

Iourov IY, Vorsanova SG, Yurov YB. 2010. Somatic genome variations in health and disease. Curr Genomics 11: 387 396.

Iourov IY, Vorsanova SG, Yurov YB. 2013. Somatic cell genomics of brain disorders: A new opportunity to clarify genetic-environmental interactions. Cytogenet Genome Res 139: 181-188.

Irokanulo EAO, Akueshi CO. 1995. Virulence of Cryptococcus neoformans serotypes A, B, C and D for four mouse strains. J Med Microbiol 43: 289-293.

Janbon G, Sherman F, Rustchenko E. 1998. Monosomy of a specific chromosome determines L-sorbose utilization: A novel regulatory mechanism in Candida albicans. Proc Natl Acad Sci 95: 5150-5155.

Janbon G, Sherman F, Rustchenko E. 1999. Appearance and properties of L-sorbose-utilizing mutants of Candida albicans obtained on a selective plate. Genetics 153: 653-664.

Jones T, Federspiel NA, Chibana H, Dungan J, Kalman S, Magee BB, Newport G, Thorstenson YR, Agabian N, Magee PT, et al. 2004. The diploid genome sequence of Candida albicans. Proc Natl Acad Sci 101: 7329-7334.

Kabir MA, Ahmad A, Greenberg JR, Wang YK, Rustchenko E. 2005. Loss and gain of chromosome 5 controls growth of Candida albicans on sorbose due to dispersed redundant negative regulators. Proc Natl Acad Sci 102: 1214712152.

Kavanaugh LA, Fraser JA, Dietrich FS. 2006. Recent evolution of the human pathogen Cryptococcus neoformans by intervarietal transfer of a 14-gene fragment. Mol Biol Evol 23: $1879-1890$.

Keeney S. 2001. Mechanism and control of meiotic recombination initiation. Curr Top Dev Biol 52: 1-53. 
Keeney S. 2008. Spol1 and the formation of DNA doublestrand breaks in meiosis. Genome Dyn Stab 2: 81-123.

Keeney S, Neale MJ. 2006. Initiation of meiotic recombination by formation of DNA double-strand breaks: Mechanism and regulation. Biochem Soc Trans 34: 523-525.

Keeney S, Giroux CN, Kleckner N. 1997. Meiosis-specific DNA double-strand breaks are catalyzed by Spo11, a member of a widely conserved protein family. Cell $\mathbf{8 8}$ : 375-384.

Kraus E, Leung WY, Haber JE. 2001. Break-induced replication: A review and an example in budding yeast. Proc Natl Acad Sci 98: 8255-8262.

Kruzel EK, Hull CM. 2010. Establishing an unusual cell type: How to make a dikaryon. Curr Opin Microbiol 13: 706-711.

Kwon-Chung KJ. 1975. A new genus, Filobasidiella, the perfect state of Cryptococcus neoformans. Mycologia 67: 1197-1200.

Kwon-Chung KJ. 1976a. Morphogenesis of Filobasidiella neoformans, the sexual state of Cryptococcus neoformans. Mycologia 68: 821-833.

Kwon-Chung KJ. 1976b. A new species of Filobasidiella, the sexual state of Cryptococcus neoformans B and C serotypes. Mycologia 68: 943-946.

Kwon-Chung JK, Bennett JE. 1978. Distribution of $\alpha$ and a mating types of Cryptococcus neoformans among natural and clinical isolates. Am J Epidemiol 108: 337-340.

Kwon-Chung KJ, Bennett JE. 1984. Epidemiologic differences between the two varieties of Cryptococcus neoformans. Am J Epidemiol 120: 123-130.

Lee HO, Davidson JM, Duronio RJ. 2009. Endoreplication: Polyploidy with purpose. Genes Dev 23: 2461-2477.

Lee SC, Ni M, Li W, Shertz C, Heitman J. 2010. The evolution of sex: A perspective from the fungal kingdom. Microbiol Mol Biol Rev 74: 298-340.

Lengeler KB, Cox GM, Heitman J. 2001. Serotype AD strains of Cryptococcus neoformans are diploid or aneuploid and are heterozygous at the mating-type locus. Infect Immun 69: $115-122$.

Li W, Averette AF, Desnos-Ollivier M, Ni M, Dromer F, Heitman J. 2012. Genetic diversity and genomic plasticity of Cryptococcus neoformans AD hybrid strains. G3 (Bethesda) 2: 83-97.

Lin X, Hull CM, Heitman J. 2005. Sexual reproduction between partners of the same mating type in Cryptococcus neoformans. Nature 434: 1017-1021.

Lin X, Nielsen K, Patel S, Heitman J. 2008. Impact of mating type, serotype, and ploidy on the virulence of Cryptococcus neoformans. Infect Immun 76: 2923-2938.

Lin X, Patel S, Litvintseva AP, Floyd A, Mitchell TG, Heitman J. 2009. Diploids in the Cryptococcus neoformans serotype A population homozygous for the $\alpha$ mating type originate via unisexual mating. PLoS Pathog 5: e1000283.

Llorente B, Smith C, Symington L. 2008. Break-induced replication: What is it and what is it for? Cell Cycle 7: 859-864.

Magee BB, Magee PT. 2000. Induction of mating in Candida albicans by construction of MTLa and MTL $\alpha$ strains. Science 289: 310-313.
Magwene PM, Kayıkçı Ö, Granek JA, Reininga JM, Scholl Z, Murray D. 2011. Outcrossing, mitotic recombination, and life-history trade-offs shape genome evolution in Saccharomyces cerevisiae. Proc Natl Acad Sci 108: 19871992.

Malik SB, Pightling AW, Stefaniak LM, Schurko AM, Logsdon JM Jr, 2008. An expanded inventory of conserved meiotic genes provides evidence for sex in Trichomonas vaginalis. PLoS ONE 3: e2879.

Mancera E, Bourgon R, Brozzi A, Huber W, Steinmetz LM. 2008. High-resolution mapping of meiotic crossovers and non-crossovers in yeast. Nature 454: 479-485.

Marichal P, Vanden Bossche H, Odds FC, Nobels G, Warnock DW, Timmerman V, Van Broeckhoven C, Fay S, Mose-Larsen P. 1997. Molecular biological characterization of an azole-resistant Candida glabrata isolate. Antimicrob Agents Chemother 41: 2229-2237.

Miller MG, Johnson AD. 2002. White-opaque switching in Candida albicans is controlled by mating-type locus homeodomain proteins and allows efficient mating. Cell 110: $293-302$.

Miller MP, Amon A, Unal E. 2013. Meiosis I: When chromosomes undergo extreme makeover. Curr Opin Cell Biol 25: 687-696.

Mondon P, Petter R, Amalfitano G, Luzzati R, Concia E, Polacheck I, Kwon-Chung KJ. 1999. Heteroresistance to fluconazole and voriconazole in Cryptococcus neoformans. Antimicrob Agents Chemother 43: 1856-1861.

Morrow CA, Fraser JA. 2013. Ploidy variation as an adaptive mechanism in human pathogenic fungi. Sem Cell Dev Biol 24: 339-346.

Morschhäuser J. 2010. Regulation of white-opaque switching in Candida albicans. Med Microbiol Immun 199: 165 172.

Muzzey D, Schwartz K, Weissman J, Sherlock G. 2013. Assembly of a phased diploid Candida albicans genome facilitates allele-specific measurements and provides a simple model for repeat and indel structure. Genome Biol 14: R97.

Neiman AM. 2011. Sporulation in the budding yeast Saccharomyces cerevisiae. Genetics 189: 737-765.

Ngamskulrungroj P, Chang Y, Hansen B, Bugge C, Fischer E, Kwon-Chung KJ. 2012a. Characterization of the chromosome 4 genes that affect fluconazole-induced disomy formation in Cryptococcus neoformans. PLoS ONE 7: e33022.

Ngamskulrungroj P, Chang Y, Hansen B, Bugge C, Fischer E, Kwon-Chung KJ. 2012b. Cryptococcus neoformans Yop1, an endoplasmic reticulum curvature-stabilizing protein, participates with Seyl in influencing fluconazole-induced disomy formation. FEMS Yeast Res 12: 748-754.

Ni M, Feretzaki M, Sun S, Wang X, Heitman J. 2011. Sex in fungi. Annu Rev Genet 45: 405-430.

Ni M, Feretzaki M, Li W, Floyd-Averette A, Mieczkowski P, Dietrich FS, Heitman J. 2013. Unisexual and heterosexual meiotic reproduction generate aneuploidy and phenotypic diversity de novo in the yeast Cryptococcus neoformans. PLoS Biol 11: e1001653.

Nielsen K, Heitman J. 2007. Sex and virulence of human pathogenic fungi. Adv Genet 57: 143-173. 
R.J. Bennett et al.

O'Gorman CM, Fuller HT, Dyer PS. 2008. Discovery of a sexual cycle in the opportunistic fungal pathogen Aspergillus fumigatus. Nature 457: 471-474.

Okagaki LH, Nielsen K. 2012. Titan cells confer protection from phagocytosis in Cryptococcus neoformans infections. Eukaryot Cell 11: 820-826.

Okagaki LH, Wang Y, Ballou ER, O'Meara TR, Bahn Y-S, Alspaugh JA, Xue C, Nielsen K. 2011. Cryptococcal titan cell formation is regulated by G-protein signaling in response to multiple stimuli. Eukaryot Cell 10: 1306-1316.

Otto SP. 2007. The evolutionary consequences of polyploidy. Cell 131: 452-462.

Papa KE. 1973. The parasexual cycle in Aspergillus flavus. Mycologia 65: 1201-1205.

Papa KE. 1978. The parasexual cycle in Aspergillus parasiticus. Mycologia 70: 766-773.

Pavelka N, Rancati G, Zhu J, Bradford WD, Saraf A, Florens L, Sanderson BW, Hattem GL, Li R. 2010. Aneuploidy confers quantitative proteome changes and phenotypic variation in budding yeast. Nature 468: 321-325.

Perepnikhatka V, Fischer FJ, Niimi M, Baker RA, Cannon RD, Wang YK, Sherman F, Rustchenko E. 1999. Specific chromosome alterations in fluconazole-resistant mutants of Candida albicans. J Bacteriol 181: 4041-4049.

Petronczki M, Siomos MF, Nasmyth K. 2003. Un menage a quatre: The molecular biology of chromosome segregation in meiosis. Cell 112: 423-440.

Pontecorvo G, Sermonti G. 1954. Parasexual recombination in Penicillium chrysogenum. J Gen Microbiol 11: 94-104.

Pontecorvo G, Roper JA, Forbes E. 1953a. Genetic recombination without sexual reproduction in Aspergillus niger. $J$ Gen Microbiol 8: 198-210.

Pontecorvo G, Roper JA, Hemmons LM, MacDonald KD, Bufton AW. 1953b. The genetics of Aspergillus nidulans. Adv Genet 5: 141-238.

Porman AM, Alby K, Hirakawa M, Bennett RJ. 2011. Discovery of a phenotypic switch regulating sexual mating in the opportunistic fungal pathogen Candida tropicalis. Proc Natl Acad Sci 108: 21158-21163.

Puig P-E, Guilly M-N, Bouchot A, Droin N, Cathelin D, Bouyer F, Favier L, Ghiringhelli F, Kroemer G, Solary E, et al. 2008. Tumor cells can escape DNA-damaging cisplatin through DNA endoreduplication and reversible polyploidy. Cell Biol Int 32: 1031-1043.

Purnell DM, Martin GM. 1973. Heterozygous diploid strains of Aspergillus nidulans: Enhanced virulence for mice in comparison to a prototrophic haploid strain. Mycopathol Mycol Appl 49: 307-319.

Ramesh MA, Malik S-B, Logsdon JM Jr. 2005. A phylogenomic inventory of meiotic genes: Evidence for sex in Giardia and an early eukaryotic origin of meiosis. Curr Biol 15: 185-191.

Ramírez-Zavala B, Reuss O, Park Y-N, Ohlsen K, Morschhäuser J. 2008. Environmental induction of whiteopaque switching in Candida albicans. PLoS Pathog 4: e1000089.

Rancati G, Pavelka N, Fleharty B, Noll A, Trimble R, Walton K, Perera A, Staehling-Hampton K, Seidel CW, Li R. 2008. Aneuploidy underlies rapid adaptive evolution of yeast cells deprived of a conserved cytokinesis motor. Cell 135: $879-893$.
Reedy JL, Floyd AM, Heitman J. 2009. Mechanistic plasticity of sexual reproduction and meiosis in the Candida pathogenic species complex. Curr Biol 19: 891-899.

Richard G-F, Kerrest A, Lafontaine I, Dujon B. 2005. Comparative genomics of hemiascomycete yeasts: Genes involved in DNA replication, repair, and recombination. Mol Biol Evol 22: 1011-1023.

Rustchenko E. 2007. Chromosome instability in Candida albicans. FEMS Yeast Res 7: 2-11.

Rustchenko-Bulgac EP, Sherman F, Hicks JB. 1990. Chromosomal rearrangements associated with morphological mutants provide a means for genetic variation of Candida albicans. J Bacteriol 172: 1276-1283.

Sanz M, Valle R, Roncero C. 2007. Promoter heterozygosity at the Candida albicans CHS7 gene is translated into differential expression between alleles. FEMS Yeast Res 7: 993-1003.

Schoustra SE, Debets AJ, Slakhorst M, Hoekstra RF. 2007. Mitotic recombination accelerates adaptation in the fungus Aspergillus nidulans. PLoS Genet 3: e68.

Schurko AM, Logsdon JM. 2008. Using a meiosis detection toolkit to investigate ancient asexual "scandals" and the evolution of sex. BioEssays 30: 579-589.

Seervai RNH, Jones SK, Hirakawa MP, Porman AM, Bennett RJ. 2013. Parasexuality and ploidy change in Candida tropicalis. Eukaryot Cell 12: 1629-1640.

Selmecki A, Bergmann S, Berman J. 2005. Comparative genome hybridization reveals widespread aneuploidy in Candida albicans laboratory strains. Mol Microbiol 55: 1553-1565.

Selmecki A, Forche A, Berman J. 2006. Aneuploidy and isochromosome formation in drug-resistant Candida albicans. Science 313: 367-370.

Selmecki AM, Gerami-Nejad M, Paulsen C, Forche A, Berman J. 2008. An isochromosome confers drug resistance in vivo by amplification of two genes, ERG11 and TAC1. Mol Microbiol 68: 624-641.

Selmecki A, Dulmage K, Cowen L, Anderson JB, Berman J. 2009a. Aneuploidy provides increased fitness during the evolution of antifungal drug resistance. PLoS Genet 5: e1000705.

Selmecki AM, Dulmage K, Cowen LE, Anderson JB, Berman J. 2009b. Acquisition of aneuploidy provides increased fitness during the evolution of antifungal drug resistance. PLoS Genet 5: e1000705.

Semighini CP, Averette AF, Perfect JR, Heitman J. 2011. Deletion of Cryptococcus neoformans AIF ortholog promotes chromosome aneuploidy and fluconazole-resistance in a metacaspase-independent manner. PLoS Pathog 7: e1002364.

Sheltzer JM, Amon A. 2011. The aneuploidy paradox: Costs and benefits of an incorrect karyotype. Trends Genet 27: $446-453$.

Sheltzer JM, Blank HM, Pfau SJ, Tange Y, George BM, Humpton TJ, Brito IL, Hiraoka Y, Niwa O, Amon A. 2011. Aneuploidy drives genomic instability in yeast. Science 333: $1026-1030$.

Sherwood RK, Bennett RJ. 2009. Fungal meiosis and parasexual reproduction-lessons from pathogenic yeast. Curr Opin Microbiol 12: 599-607. 
Fungal Ploidy and Parasexual Cycles

Sherwood RK, Scaduto CM, Torres SE, Bennett RJ. 2014 Convergent evolution of a fused sexual cycle promotes the haploid lifestyle. Nature 506: 387-390.

Sionov E, Chang YC, Garraffo HM, Kwon-Chung KJ. 2009. Heteroresistance to fluconazole in Cryptococcus neoformans is intrinsic and associated with virulence. Antimicrob Agents Chemother 53: 2804-2815.

Sionov E, Lee H, Chang YC, Kwon-Chung KJ. 2010. Cryptococcus neoformans overcomes stress of azole drugs by formation of disomy in specific multiple chromosomes. PLoS Pathog 6: e1000848.

Sionov E, Chang YC, Kwon-Chung KJ. 2013. Azole heteroresistance in Cryptococcus neoformans: Emergence of resistant clones with chromosomal disomy in the mouse brain during fluconazole treatment. Antimicrob Agents Chemother 57: 5127-5130.

Springer M, Weissman JS, Kirschner MW. 2010. A general lack of compensation for gene dosage in yeast. Mol Syst Biol 6: 368.

Staib P, Kretschmar M, Nichterlein T, Hof H, Morschhäuser J. 2002. Host versus in vitro signals and intrastrain allelic differences in the expression of a Candida albicans virulence gene. Mol Microbiol 44: 1351-1366.

Storchova Z, Breneman A, Cande J, Dunn J, Burbank K, O’Toole E, Pellman D. 2006. Genome-wide genetic analysis of polyploidy in yeast. Nature 443: 541-547.

Straub T, Becker PB. 2007. Dosage compensation: The beginning and end of generalization. Nat Rev Genet 8: 47-57.

Sugui JA, Losada L, Wang W, Varga J, Ngamskulrungroj P, Abu-Asab M, Chang YC, O'Gorman CM, Wickes BL, Nierman WC, et al. 2011. Identification and characterization of an Aspergillus fumigatus "supermater" pair. MBio 2: e00234-11.

Sun S, Xu J. 2009. Chromosomal rearrangements between serotype A and D strains in Cryptococcus neoformans. PLoS ONE 4: e5524.

Suzuki T, Nishibayashi S, Kuroiwa T, Kanbe T, Tanaka K. 1982. Variance of ploidy in Candida albicans. J Bacteriol 152: $893-896$

Suzuki T, Kobayashi I, Kanbe T, Tanaka K. 1989. High frequency variation of colony morphology and chromosome reorganization in the pathogenic yeast Candida albicans. J Gen Microbiol 135: 425-434.

Tan Z, Hays M, Cromie GA, Jeffery EW, Scott AC, Skupin A, Ahyong V, Sirr A, Dudley AM. 2013. Aneuploidy underlies a multicellular phenotypic switch. Proc Natl Acad Sci 110: $12367-12372$.

Tanaka R, Taguchi H, Takeo K, Miyaji M, Nishimura K. 1996. Determination of ploidy in Cryptococcus neoformans by flow cytometry. J Med Vet Mycol 34: 299-301.

Toffaletti DL, Nielsen K, Dietrich F, Heitman J, Perfect JR. 2004. Cryptococcus neoformans mitochondrial genomes from serotype A and D strains do not influence virulence. Curr Genet 46: 193-204.

Torres EM, Williams BR, Amon A. 2008. Aneuploidy: Cells losing their balance. Genetics 179: 737-746.

Torres EM, Dephoure N, Panneerselvam A, Tucker CM, Whittaker CA, Gygi SP, Dunham MJ, Amon A. 2010 Identification of aneuploidy-tolerating mutations. Cell 143: $71-83$.
Tzung KW, Williams RM, Scherer S, Federspiel N, Jones T, Hansen N, Bivolarevic V, Huizar L, Komp C, Surzycki R, et al. 2001. Genomic evidence for a complete sexual cycle in Candida albicans. Proc Natl Acad Sci 98: 3249-3253.

Ullah Z, Lee CY, Lilly MA, DePamphilis ML. 2009. Developmentally programmed endoreduplication in animals. Cell Cycle 8: 1501-1509.

vanden Bossche H, Marichal P, Odds FC, Le Jeune L, Coene MC. 1992. Characterization of an azole-resistant Candida glabrata isolate. Antimicrob Agents Chemother 36: 2602 2610.

van Werven FJ, Amon A. 2011. Regulation of entry into gametogenesis. Phil Trans R Soc Lond B Biol Sci 366: 3521-3531.

Villeneuve AM, Hillers KJ. 2001. Whence meiosis? Cell 106: 647-650.

White TC. 1997. The presence of an R467K amino acid substitution and loss of allelic variation correlate with an azole-resistant lanosterol $14 \alpha$ demethylase in Candida albicans. Antimicrob Agents Chemother 41: 1488-1494.

Wickes B, Petter R. 1996. Genomic variation in C. albicans. Curr Top Med Mycol 7: 71-86.

Wu C-Y, Rolfe PA, Gifford DK, Fink GR. 2010. Control of transcription by cell size. PLoS Biol 8: e1000523.

Xie J, Du H, Guan G, Tong Y, Kourkoumpetis TK, Zhang L, Bai FY, Huang G. 2012. N-acetylglucosamine induces white-to-opaque switching and mating in Candida tropicalis, providing new insights into adaptation and fungal sexual evolution. Eukaryot Cell 11: 773-782.

Xie J, Tao L, Nobile CJ, Tong Y, Guan G, Sun Y, Cao C, Hernday AD, Johnson AD, Zhang L, et al. 2013. Whiteopaque switching in natural MTLa/ $\alpha$ isolates of Candida albicans: Evolutionary implications for roles in host adaptation, pathogenesis, and sex. PLoS Biol 11: e1001525.

Yamamoto M. 1996. Regulation of meiosis in fission yeast. Cell Struct Funct 21: 431-436.

Yang F, Kravets A, Bethlendy G, Welle S, Rustchenko E. 2013. Chromosome 5 monosomy of Candida albicans controls susceptibility to various toxic agents including major antifungals. Antimicrob Agents Chemother 57: 5026-5036.

Yona AH, Manor YS, Herbst RH, Romano GH, Mitchell A Kupiec M, Pilpel Y, Dahan O. 2012. Chromosomal duplication is a transient evolutionary solution to stress. Proc Natl Acad Sci 109: 21010-21015.

Zaragoza O, Nielsen K. 2013. Titan cells in Cryptococcus neoformans: Cells with a giant impact. Curr Opin Microbiol 16: 409-413.

Zaragoza O, García-Rodas R, Nosanchuk JD, Cuenca-Estrella M, Rodríguez-Tudela JL, Casadevall A. 2010. Fungal cell gigantism during mammalian infection. PLoS Pathog 6: e1000945.

Zhu J, Pavelka N, Bradford WD, Rancati G, Li R. 2012. Karyotypic determinants of chromosome instability in aneuploid budding yeast. Plos Genet 8: e1002719.

Zielke N, Edgar BA, DePamphilis ML. 2013. Endoreplication. Cold Spring Harb Perspect Biol 5: a012948.

Zörgö E, Chwialkowska K, Gjuvsland AB, Garré E, Sunnerhagen P, Liti G, Blomberg A, Omholt SW, Warringer J. 2013. Ancient evolutionary trade-offs between yeast ploidy states. PLoS Genet 9: e1003388. 


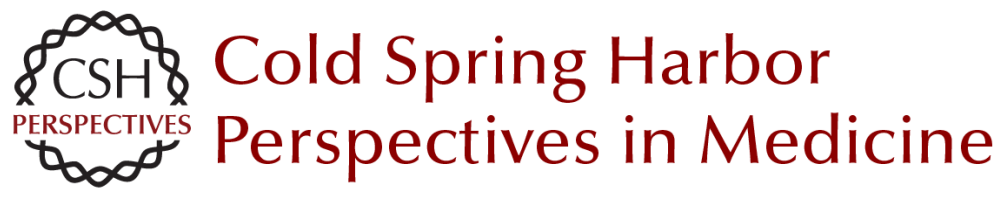

\section{Rapid Mechanisms for Generating Genome Diversity: Whole Ploidy Shifts, Aneuploidy, and Loss of Heterozygosity}

Richard J. Bennett, Anja Forche and Judith Berman

Cold Spring Harb Perspect Med 2014; doi: 10.1101/cshperspect.a019604 originally published online July 31, 2014

\begin{tabular}{|c|c|}
\hline Human Fungal Pathogens & \\
\hline $\begin{array}{l}\text { Evolutionary Perspectives on Human Fungal } \\
\text { Pathogens } \\
\text { John W. Taylor }\end{array}$ & $\begin{array}{l}\text { Thermally Dimorphic Human Fungal Pathogens-- } \\
\text { Polyphyletic Pathogens with a Convergent } \\
\text { Pathogenicity Trait } \\
\text { Anita Sil and Alex Andrianopoulos }\end{array}$ \\
\hline $\begin{array}{l}\text { Black Molds and Melanized Yeasts Pathogenic to } \\
\text { Humans } \\
\text { Anuradha Chowdhary, John Perfect and G. Sybren } \\
\text { de Hoog }\end{array}$ & $\begin{array}{l}\text { Mechanisms of Antifungal Drug Resistance } \\
\text { Leah E. Cowen, Dominique Sanglard, Susan J. } \\
\text { Howard, et al. }\end{array}$ \\
\hline $\begin{array}{l}\text { Fungal Pathogens: Survival and Replication } \\
\text { within Macrophages } \\
\text { Andrew S. Gilbert, Robert T. Wheeler and Robin C. } \\
\text { May }\end{array}$ & $\begin{array}{l}\text { Treatment Principles for Candida and } \\
\text { Cryptococcus } \\
\text { Laura C. Whitney and Tihana Bicanic }\end{array}$ \\
\hline $\begin{array}{l}\text { Innate Defense against Fungal Pathogens } \\
\text { Rebecca A. Drummond, Sarah L. Gaffen, Amy G. } \\
\text { Hise, et al. }\end{array}$ & $\begin{array}{l}\text { The Human Mycobiome } \\
\text { Patrick C. Seed }\end{array}$ \\
\hline $\begin{array}{l}\text { Antifungal Pharmacokinetics and } \\
\text { Pharmacodynamics } \\
\text { Alexander J. Lepak and David R. Andes }\end{array}$ & $\begin{array}{l}\text { Treatment Principles for the Management of Mold } \\
\text { Infections } \\
\quad \text { Dimitrios P. Kontoyiannis and Russell E. Lewis }\end{array}$ \\
\hline $\begin{array}{l}\text { Human Fungal Pathogens of Mucorales and } \\
\text { Entomophthorales } \\
\text { Leonel Mendoza, Raquel Vilela, Kerstin Voelz, et } \\
\text { al. }\end{array}$ & $\begin{array}{l}\text { Adaptive Immunity to Fungi } \\
\text { Akash Verma, Marcel Wüthrich, George Deepe, et } \\
\text { al. }\end{array}$ \\
\hline $\begin{array}{l}\text { Functional Profiling of Human Fungal Pathogen } \\
\text { Genomes } \\
\text { Alexi I. Goranov and Hiten D. Madhani }\end{array}$ & $\begin{array}{l}\text { The Candida Pathogenic Species Complex } \\
\text { Siobhán A. Turner and Geraldine Butler }\end{array}$ \\
\hline $\begin{array}{l}\text { Aspergillus fumigatus and Related Species } \\
\text { Janyce A. Sugui, Kyung J. Kwon-Chung, Praveen } \\
\text { R. Juvvadi, et al. }\end{array}$ & $\begin{array}{l}\text { Fungal Morphogenesis } \\
\text { Xiaorong Lin, J. Andrew Alspaugh, Haoping Liu, et } \\
\text { al. }\end{array}$ \\
\hline
\end{tabular}

For additional articles in this collection, see http://perspectivesinmedicine.cshlp.org/cgi/collection/ 